\section{Congratulatory Comment}

\title{
Congratulatory comment from Korean Nurses Association
}

Kyung Rim Shin

President of Korean Nurses Association

On behalf of nursing professions in Korea, I would like to express my sincerest congratulations to the foundation of the 'Korean Society of Global Health (KSGH) Journal, named Journal of Global Health Science (JGHS).' This journal will contribute to the promotion of an effective and academic communication between the international society and the international public health community.

As we have already experienced through severe acute respiratory syndrome in 2003 and Middle East respiratory syndrome in 2015, diseases easily cross borders and spread out in any countries, and the necessity of cooperation for disease control on a global scale has been raised early on.

The KSGH has been established in March 2013, as the role of international public health has been greatly increased due to the urgent call for joint action not only against communicable disease but also against non-communicable disease in recent years.

Since the launch of the KSGH, various researchers, experts, policy makers, and field practitioners from the field of public health have gathered to exchange and share information and provide training opportunities in order to gain attention and carry out activities both systematically and internationally.

However, many countries and regions still have difficulty in gaining access to health care. The countries and regions concerned must work hard to solve the problem, but the solution becomes more effective when other countries show sympathy and cooperate.

The publication of the JGHS at this moment is very timely and desirable in terms of strengthening international cooperation through active academic exchanges with the international community.

Finally, I would like to express my sincere gratitude to President Sung Tae Hong of the KSGH and all the relevant staffs who have done their best for the foundation of JGHS. Thank you. 